УДК 331.101.264:316.346-053.9(47+57)

\title{
РЕГИОНАЛЬНЫЙ ПРОФИЛЬ ТРУДОВОГО ПОВЕДЕНИЯ НАСЕЛЕНИЯ ПОЖИЛОГО ВОЗРАСТА
}

\author{
Клемашева Елена Игоревна 1 , \\ eik15@tpu.ru \\ Иванкина Любовь Ивановна ${ }^{1}$, \\ ivankina@tpu.ru \\ Таран Екатерина Александровна², \\ etaran@hse.ru \\ Кашапова Эльмира Рамисовна1, \\ elmira@tpu.ru \\ Касати Фабио 1 , \\ kasati@tpu.ru \\ ${ }^{1}$ Национальный исследовательский Томский политехнический университет, \\ Россия, 634050, Томск, пр. Ленина, 30 \\ 2 Национальный исследовательский университет «Высшая школа экономики», \\ Россия, 101000, Москва, ул. Мясницкая 20
}

Клемашева Елена Игоревна, кандидат экономических наук, доцент отделения социальногуманитарных наук Школы базовой инженерной подготовки Национального исследовательского Томского политехнического университета.

Иванкина Любовь Ивановна, доктор философских наук, профессор, ведущий научный сотрудник Международной научно-образовательной лаборатории технологий улучшения благополучия пожилых людей Национального исследовательского Томского политехнического университета.

Таран Екатерина Александровна, кандидат экономических наук, научный сотрудник Института статистических исследований и экономики знаний Национального исследовательского университета «Высшая школа экономики».

Кашапова Эльмира Рамисовна, младший научный сотрудник Международной научнообразовательной лаборатории технологий улучшения благополучия пожилых людей Национального исследовательского Томского политехнического университета.

Касати Фабио, PhD, ведущий научный сотрудник Международной научно-образовательной лаборатории технологий улучшения благополучия пожилых людей Национального исследовательского Томского политехнического университета.

Проанализирована на региональном уровне структура трудовой занятости людей пожилого возраста. В меняющихся объективных (достижение пенсионного возраста) и субъективных (переживание перехода в новый статус и принятие новых социально-ролевых функций) условиях структурирования жизнедеятельности меняется и трудовая занятость людей старшего поколения. Цель: предложить типологию стратегий трудового поведения на предпенсионном этапе и этапе выхода на пенсию на основании выявления мотивации вовлеченности в трудовую деятельность. Методы: анализ данных социологического опроса, описательная статистика. Социологические опросы проведены с 2015 по 2019 г. в Томске и Томской области сотрудниками Международной научнообразовательной лаборатории технологий улучшения благополучия пожилых людей при Томском политехническом университете и позволили сформировать эмпирическую базу исследования. Основные результаты социологического измерения получены с использованием статистического пакета 
SPSS-26. Результаты и выводы: анализ данных социологического опроса позволил выявить закономерности в предпочитаемых людьми формах трудового поведения, провести типологию и составить профиль трудового поведения населения старшего возраста Томской области в контексте доходного неравенства. Выделено четыре типа трудового поведения, показатели, их характеризующие, субъективные и объективные факторы. Сделан вывод о необходимости выстраивать новую модель жизненного пути, в которой пожилой человек не выступал бы в роли иждивенца, а рассматривался как самостоятельный, активный член общества - на это ориентированы международная программа активного долголетия и программа по реализации стратегий действий в интересах граждан пожилого возраста в РФ до 2025 г. Полученные результаты позволяют выделить институциональные условия вовлечения людей старшего возраста в социально-экономическую систему. Делается вывод, что для этого необходимо обеспечить экономическую независимость пожилого человека за счет создания условий для продления трудовой жизни в соответствии с желанием и способностью кее продолжению, а также за счет накопления в течение трудовой жизни капитала, обеспечивающего высокий доход после ухода из сферы трудовой занятости, который повысит жизнестойкость пожилого человека и сгладит неравенство.

Ключевые слова: Трудовое поведение, население пожилого возраста, типология трудового поведения, жизнестойкость, вовлечение, трудовой потенциал.

\section{Актуальность и постановка задачи исследования}

Деятельность пожилых людей в рамках рынка труда реализуется на основе трудового поведения, под которым будем понимать комплекс действий по осуществлению приносящей доход деятельности по найму с заключением трудового договора, в условиях самозанятости и малого предпринимательства, а также включение в данный комплекс процесса поиска работы [1, 2]. В РФ, по данным Росстата [3], в 2018 г. в среднем по стране работала треть населения, достигшего пенсионного возраста, а в 2020 г. работал каждый пятый человек (увеличение, в том числе, связано с увеличением пенсионного возраста).

Использование трудового потенциала пожилых людей в условиях новой демографической ситуации стало актуальной задачей для страны, реализации которой препятствуют многие факторы - прежде всего практика возрастной дискриминации - эйджизм. Данная практика распространена во всем мире и имеет серьезные последствия для вовлечения людей пенсионного возраста в трудовую занятость [4-7].

Поведение пожилых людей на рынке труда привлекает исследователей широким спектром проявлений, среди которых причины, мотивация и цели трудовой занятости, а также выявление отношения пожилых людей к продолжению трудовой активности [8-13]. В ряде исследований [14-15] рассматриваются факторы предложения труда для категории работников-пенсионеров и вопросы разрыва в оплате между работниками по гендерному и возрастному признакам. Данные направления исследований представлены достаточно широко в научной литературе в аспекте изучения региональных особенностей трудового поведения лиц, вышедших из трудоспособного возраста [16-18].

Трудовая занятость людей пожилого возраста относится к одному из ключевых индикаторов измерения активного долголетия, и реализация трудового потенциала населения третьего возраста в условиях сжатия предложения труда более молодой возрастной группе актуализирует необходимость выявления особенностей трудового поведения людей пенсионного возраста и разработки институциональных условий и технологических решений вовлечения населения старшей возрастной группы в трудовые практики с учетом доказанного высокого уровня качества работы пожилых людей [19].

Данная задача решается в условиях глобальных вызовов, связанных со старением населения, и отягощается на современном этапе процессами пандемии COVID-19, ко- 
торые, помимо традиционных, формируют новые барьеры вовлеченности людей пожилого возраста в трудовую активность.

Реализация трудового потенциала населения старшего возраста через трудовое поведение происходит под влиянием объективных и субъективных факторов, формируя тем самым типологию трудового поведения.

В задачи исследования входило выявление особенностей трудового поведения в условиях, когда наряду с очевидной тенденцией сокращения уровня занятости по достижении пенсионного возраста меняется структура занятости у тех, кто продолжает трудовую активность и связан с рынком труда по достижению пенсионного возраста.

\section{Особенности трудовой занятости (по данным соцопроса)}

Для сравнения позиций работающих непенсионеров, работающих пенсионеров и неработающих пенсионеров относительно трудовой занятости обратимся к базе данных социологического опроса, проведенного в Томске и Томской области в 2018 г. сотрудниками Международной научно-образовательной лаборатории технологий улучшения благополучия пожилых людей.

В опросе приняли участие 610 чел., из них 33,6 \% - работающих непенсионеров, $33,6 \%$ - работающих пенсионеров и $32,8 \%$ - неработающих пенсионеров. Возраст работающих непенсионеров составил 50-54 года для женщин и 50-59 лет - для мужчин, возраст женщин- пенсионеров составил 55+ и мужчин - 60+. Выборка респондентов предпенсионного возраста (работающие непенсионеры) по гендерному признаку представлена в равном соотношении женщин и мужчин. Гендерная принадлежность работающих респондентов пенсионного возраста представлена в соотношении 58,4 \% женщин и 41,6 \% - мужчин; среди неработающих пенсионеров женщины составили 62,6 \% от выборки по данной группе и 37,4 \% - мужчины.

Работающим непенсионерам и работающим пенсионерам предлагалось оценить степень удовлетворенности трудовой деятельностью, учитывая разные аспекты проявления - от удовлетворенности отношениями в трудовом коллективе до удаленности работы от места проживания. Распределение предпочтений представлено на диаграмме (рис. 1).

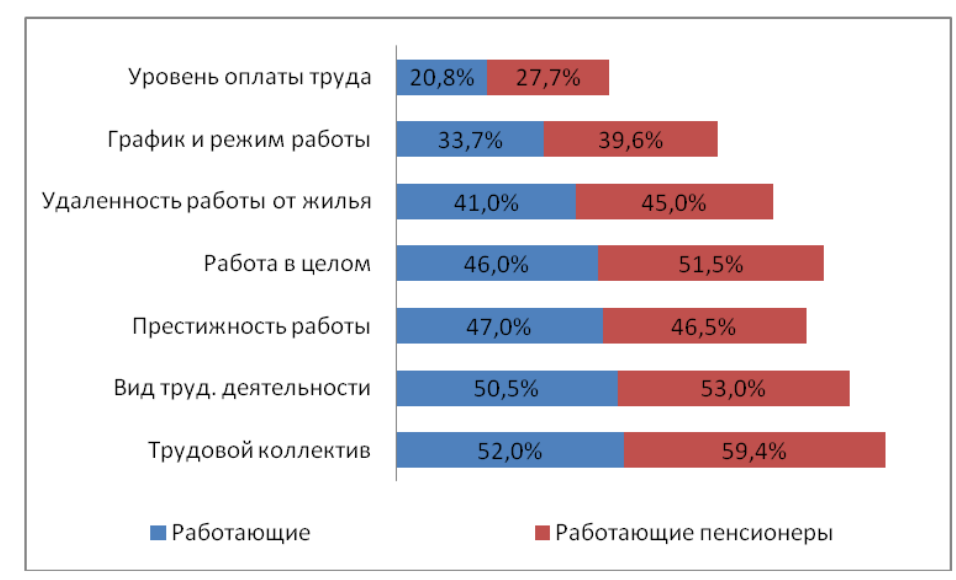

Pис. 1. Параметры удовлетворенности работой

(ответы «совершенно устраивает» и «скорее устраивает» на вопрос «В какой степени вас устраивают следующие аспекты вашей работы?»), \%

Fig. 1. Job satisfaction parameters

(answers «perfectly satisfied» and «rather satisfied» to the question «To what extent are you satisfied with the following aspects of your work?») in \% 
Как видно из данных, приведенных на диаграмме, работающие пенсионеры в целом довольны работой (51,5 \% опрошенных), отношениями в трудовом коллективе $(58,4 \%)$ и в меньшей степени - графиком и режимом работы $(39,5 \%)$.

На вопрос «Чего не хватает для трудоустройства?» ответы распределились следующим образом (рис. 2).

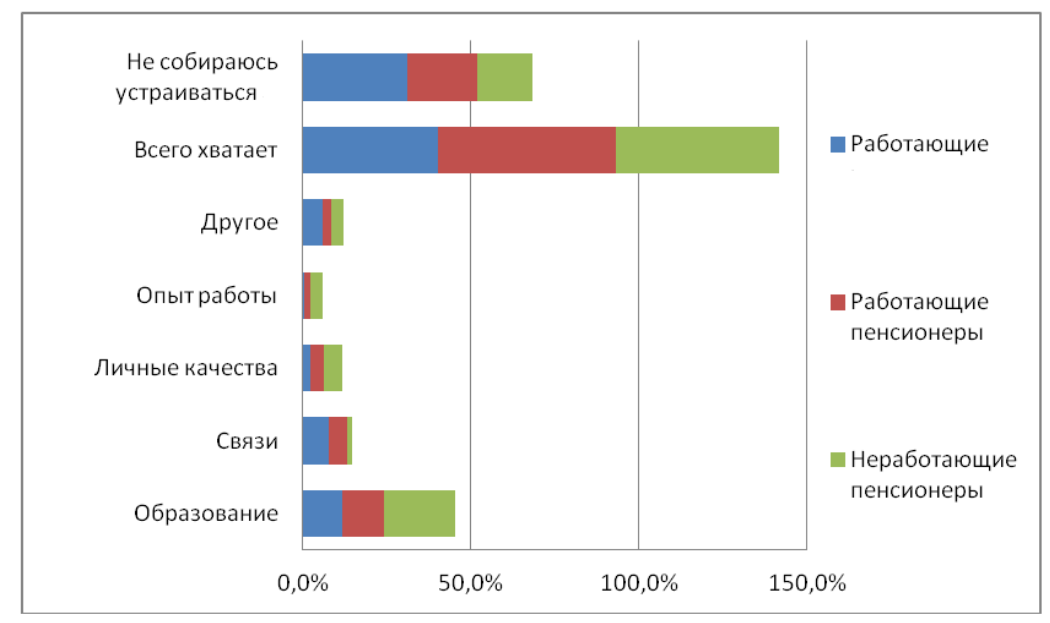

Puc. 2. Распределение ответов на вопрос

«Чего не хватает для трудоустройства?»

Fig. 2. Distribution of respondents' answers to the question «What is missing for employment?»

Все три группы респондентов указали в качестве одного из препятствий в трудоустройстве образование.

Признавая недостаточность образования, относят ли респонденты данное требование к себе? По данным опроса, в дополнительном обучении заинтересованы 18,8 \% работающих непенсионеров, 13,4 \% - работающих пенсионеров и 12,1 \% - неработающих пенсионеров. Можно сделать вывод о том, что данный способ повышения своего трудового потенциала не относится к приоритетным и значимым в трудовой практике. По итогам опроса не хотят что-либо менять в текущей работе 71,3 \% работающих непенсионеров и 73,8 \% работающих пенсионеров.

32,7 \% респондентов из группы работающих непенсионеров и $35,9 \%$ работающих пенсионеров считают, что проблем с занятостью по своей специальности в регионе нет.

Большинство желающих обучаться работающих непенсионеров $(88,3 \%)$ и работающих пенсионеров (96,6 \%) предпочитают обучение на курсах повышения квалификации в заочной форме. Неработающие пенсионеры в большей степени заинтересованы в очной форме обучения (53,4 \% от респондентов в данной группе).

Результаты опроса мнения трех групп респондентов позволяют сделать вывод относительно того, что наличие альтернативных поведенческих стратегий встраивания пожилых людей в региональный социум обеспечивает сохранность трудовой активности, положительно влияя на удовлетворенность занятостью людей пожилого возраста.

\section{Типология трудового поведения}

Есть ли специфика в трудовом поведении у пожилых людей и какие особенности имеет трудовая занятость на этом этапе жизни человека? В рамках используемой методологии анализа объективность и субъективность факторов, которые оказывают влия- 
ние на реализацию человеческого потенциала посредством трудового поведения на рынке труда, «определяется тем, в состоянии ли пожилой человек повлиять на него, учитывая свои потребности, желания и т. д., а также на социальные условия, дающие возможность оказывать влияние на этот фактор» [16, с. 485].

Выявление типологии трудового поведения реализовывалось посредством анализа результатов проведенного в 2019 г. социологического опроса лиц в возрасте 50+, проживающих в городах и сельской местности Томской области.

В опросе приняло участие 450 чел. Распределение опрошенных по полу и возрасту соответствует параметрам генеральной совокупности. Контингент опрошенных на 40 \% стоит из мужчин, на $60 \%$ - из женщин. Для определения потенциального пенсионного статуса группа от 50 до 60 лет разбита на две подгруппы: 50-54 лет (20\% опрошенных) и 55-59 лет (20 \%). В этих подгруппах доля мужчин выше - до 23 \% против 17 \% женщин. В более старших возрастных группах доля мужчин закономерно падает.

Ограничения в аналитическом обобщении связаны с актуализацией проблемы доходного неравенства в рамках исследуемой возрастной группы, что потребовало выявить ключевые для анализа доходные группы репрезентативной выборки из 338 респондентов. Определение неравенства и разграничение населения по доходным группам осуществлялось на основе коэффициента Пальма, который сегодня используется наравне с индексом Джини в рамках анализа неравенства доходов [20]. Коэффициент Пальма, рассчитанный по данным Комплексного наблюдения условий жизни населения (КОУЖ) [21] для рассматриваемой выборки в Томской области, составил в 2016 г. 3,74, в 2018 г. $-2,57$.

Для анализа трудового поведения были выделены индикаторы: доход; трудовая занятость (работает/не работает); образование; гендерная принадлежность; возраст; удовлетворенность жизнью; жизненные приоритеты; мотивация трудовой занятости; применение IT-технологий и дистантных форм организации работы; структура рабочего времени. Применение данных индикаторов позволило выделить следующие четыре типа профилей трудового поведения людей пожилого возраста.

Первый тип: группа по доходу - работающие. Преобладающий возраст представителей данной группы 55-60 лет, процент от выборки в возрастной группе - 80,0 \%; вторая возрастная категория 61-72 года, процент от выборки - 30,8 \%. Гендерная особенность - преимущественно женщины - 66,7 \%. Образование высшее и среднее специальное - 26,50 \% и 23,50\% соответственно.

Удовлетворенность жизнью у данной группы высокая: большая часть спокойно или с надеждой и оптимизмом смотрит в будущее $(76,60 \%)$. Потребительская сторона их жизнедеятельности характеризуется удовлетворенностью основными составляющими, такими как жилищные условия, материальный достаток, качество питания, организация досуга $-75,60 ; 58,90 ; 82,40 ; 82,40$ \% соответственно.

Основные жизненные приоритеты связаны с продолжением трудовой активности $(57,10 \%)$ и мало связаны с иждивенческим настроем относительно помощи государства. Забота государства о пожилых людях является приоритетом только для $25 \%$ респондентов в группе.

Мотивацией к продолжению трудовой деятельности для данной группы выступает получение дохода $(71,43$ \%), что отнесем к субъективному фактору реализации трудового потенциала. В равной мере жизненными приоритетами являются активная жизненная позиция $(66,70 \%)$, материальный достаток $(62,50 \%)$ и хорошее здоровье $(62,50 \%)$, при этом оценку своему здоровью респонденты дают как «хорошее» $(18,20 \%)$ и «среднее» $(63,60 \%)$, следовательно, можно сделать предположение, что здоровье является субъективным фактором продолжения трудовых практик. 
В данной группе преобладает доля занятых полный рабочий день на ставку 88,24 \%. Должностная принадлежность описываемой группы - это специалисты $(43,80 \%)$ и руководители подразделения $(25,00 \%)$.

Относительно современных особенностей трудовых практик, подтвержденных эмпирическими данными, следует отметить, что население данной возрастной группы медленнее и в большей мере без желания переходит на новые способы использования информационно-коммуникационных технологий (ИКТ). Новая нормальность - это работать с применением ИКТ. Отмеченное изменение подтверждается большим процентом респондентов, которые используют электронные устройства в постоянной работе или занятости, $-70,60 \%$. Цифровые навыки для удаленной работы через Интернет не имеют 52,9 \% респондентов этой группы и не хотят этому научиться, и только $41,1 \%$ опрошенных умеют или выражают заинтересованность в получении новых навыков данного вида трудовой активности.

Предполагаемые пути расширения использования трудового потенциала данной группы - это привлечение к консультационным услугам в рамках организаций или деятельности в качестве наставников (тренеров). В данной возрастной группе 5,80\% респондентов были заняты репетиторством и профессиональным консультированием на безвозмездной основе.

Второй тип: группа по доходу - неработающие. Преобладающий возраст представителей данной группы - 61-72 и 73+. Гендерная особенность - преимущественно мужчины $(63,2 \%)$. Образование высшее и среднее $-38,20$ и 8,80 \% соответственно.

Удовлетворенность жизнью - высокая, но проявляются тревога и неуверенность при оценке будущего - 41,2 \%. Основные жизненные приоритеты в большей степени связаны с хорошим жильем $(66,70 \%)$ и благополучием близких $(51,90 \%)$. В условиях наличия тревоги за будущее проявляется запрос на помощь государства - «забота государства о пожилых людях», данная потребность является приоритетом для 75 \% респондентов группы.

Ключевыми потребностями выступают поиск работы (100\% от данной группы выборки), лечение (50,00 \%) - в условиях, когда свое здоровье респонденты оценивают как среднее - $64 \%$ и плохое - $16 \%$, и отдых/общение $(47,40 \%)$.

В контексте характеристики современных особенностей трудовых практик респонденты данной группы не используют электронные устройства в постоянной работе или занятости и не хотят научиться - 76,50 \%. Приобрести новые навыки и способы включения ИКТ в инструменты обеспечения занятости у большего процента не входят в число приоритетов и текущих потребностей.

Важной особенностью данной группы является то, что 5,90 \% за деньги оказывают услуги по профессиональному консультированию, хотя не относят себя к категории занятых. Отмеченная особенность позволяет подтвердить комплексность применяемого в исследовании подхода к определению трудового поведения, связанного с ограничениями восприятия населением старшего возраста современных изменений рынка труда, как относительно характера занятости - дистанционная работа, так и формы занятости - самозанятость, к которым относится консультирование на основе оплаты. Государственное нормативное оформление новых форм занятости является объективным фактором реализации трудового потенциала через рынок труда.

Третий тип: группа по доходу - работающие. Возрастная характеристика схожа с первым типом, гендерная - со вторым. Образовательная составляющая характеризуется средним специальным и средним образованием - 11,9 и 8,8 \% соответственно. Уровень образования первично выступает субъективным фактором и вторично - объективным, т. к. не всегда население старшей возрастной группы способно повысить свой уровень по причине недоступности соответствующей инфраструктуры. 
Потребительская сторона жизнедеятельности этой группы характеризуется удовлетворенностью основными составляющими, такими как жилищные условия, качество питания, организация досуга, как и у первого типа. Однако материальная удовлетворенность снижена и составляет $40,7 \%$, что согласовывается с доходной группой респондентов согласно коэффициенту Пальма.

Оценка будущего принимает характеристику второго типа - спокойно-тревожная, без запроса помощи со стороны государства. Ключевым приоритетом выступают интересная работа $(66,70 \%)$ и активная жизненная позиция $(40,00 \%)$.

Мотивацией, так же как и у первого типа, является доход (75,68 \%), но отличием от первого типа в контексте мотивации является большее внимание к общению в качестве основной причины продолжения трудовой деятельности - 18,92 против 14,92 \% респондентов первого типа.

Занятость данной группы отличается от занятости работающего населения старшего возраста первой группы по доходу. Здесь превалирует временная занятость (50 \%) и неполный рабочий день $(35,71 \%)$, что формирует предпосылки нестабильного и более низкого дохода и становится объективным фактором, т. к. категория населения 55+ в большей своей доле относится к категории пенсионеров и их трудовой потенциал пользуется более низким спросом в рамках рынка труда.

Род занятий в рамках занятости данного типа - это рабочие $(47,80 \%)$ и специалисты (34,80 \%). Особенностью данной типа является также осуществление деятельности по реализации урожая с приусадебного участка $-2,20 \%$.

Временный характер занятости, более низкие доходы могут быть следствием низкого интереса данного типа к современным трудовым навыкам и практикам - не умеют и не хотят формировать цифровые навыки и навыки удаленного способа работы 68,80 и $56,30 \%$ соответственно. Использование ИКТ занимает роль в большей степени объективного фактора, т. к. государство и работодатель создают инфраструктуру для овладения современными навыками и их использования на рабочем месте, а также политика по сглаживанию неравенства является возможным инструментом, который даст возможность обеспечить доступность средств ИКТ для населения старшей возрастной группы.

Четвертый тип: группа по доходу - неработающие. Преобладающий возраст представителей данной группы - 61-72 и 73+. Гендерная особенность, так же как у первого типа, - преимущественно женщины. Образовательная составляющая характеризуется как у третьего типа - средним специальным и средним образованием $-25,10$ и $34,10 \%$ соответственно.

Оценка будущего принимает характеристику третьего типа - спокойно-тревожная, с запросом на внимание государства к лицам старшего возраста $(82,40 \%)$. Основные жизненные приоритеты в большей степени связаны с материальным достатком $(78,10 \%)$, хорошим жильем и работой.

Активная жизненная позиция в меньшей мере интересна работающему населению данной доходной группы. Ключевыми потребностями выступают отдых и общение, лечение, обновление жилья, приобретение новых навыков и поиск работы.

В данной группе самая низкая оценка своего здоровья - 29 \%. Современные особенности трудовых практик также не входят в число жизненных приоритетов данного типа. Для данной группы характерно безвозмездно оказывать услуги по профессиональному консультированию и репетиторству, как третьему типу реализовывать урожай с приусадебного участка за деньги (2,20\%), при этом к категории занятых респонденты с учетом отмеченных ими практик себя не относят.

Выявленная типология трудового поведения отражает региональную особенность реализации трудового потенциала населения пожилого возраста. Полученные результа- 
ты формируют предпосылку к продолжению исследования с включением большего числа выборок с целью выявления факторов, способствующих формированию институциональной среды вовлечения людей старшего возраста в социально-экономическую систему с их региональной диверсификацией, которая возможна в условиях применения цифровых технологий и наличия региональных резервов недововлеченности населения старшего возраста в приносящие доход трудовые практики.

Исследование выполнено за счет гранта Российского научного фонда (проект № 19-18-00282).

\section{СПИСОК ЛИТЕРАТУРЫ}

1. Кулькова И. Поиск работы как составляющая трудового поведения (по результатам опроса, проведенного в УрФО) // Вопросы экономики. - 2008. - № 6. - С. 111-117.

2. Темницкий А.Л. Теоретико-методологические подходы к исследованию трудового поведения // Социологические исследования. - 2007. - № 6. - С. 60-71.

3. Сколько россиян работает на пенсии. Кем они трудятся зарабатывают. - URL: https://journal.tinkoff.ru/stat-penswork/ (дата обращения 15.08. 2021).

4. Иванова М.А. Спрос на пожилых работников и дискриминация по возрасту: международный опыт и российские реалии // Вопросы экономики. - 2019. - № 6. - С. 99-121.

5. Клепикова Е.А., Колосницына М.Г. Эйджизм на российском рынке труда: дискриминация в заработной плате // Российский журнал менеджмента. - 2017. - №15 (1). - С. 69-88.

6. Клепикова Е.А. Возрастная дискриминация при найме: результаты экспериментального исследования // Экономическая политика. - 2019. - Т. 14. - № 2. - С. 64-89.

7. Пашко Т.Ю. Возрастная дискриминация на рынке труда: специфика эйджизма в России // Сборник научных трудов по материалам II Международной научно-практической конференции: Социальноэкономические проблемы в современной науке. - М.: Открытое знание, 2017. - С. 77-78.

8. Козина И.М., Зангиева И.К. Государственное и рыночное регулирование трудовой активности пенсионеров // Журнал исследований социальной политики. - 2018. - № 16 (1). - С. 7-22.

9. Лукьянова А. Занятость населения старшего возраста. Центр трудовых исследований НИУ ВШЭ. URL: $\quad$ https://isp.hse.ru/data/2020/04/28/1544886314/03\%20Lukyanova_Doklad\%20KPAD_28-042020.pdf (дата обращения 12.08. 2021).

10. Чистова Е.В. Занятость лиц пенсионного возраста: спрос и предложение на рынке труда России // Экономика и бизнес: теория и практика. - 2019. - № 10-2 (56). - С. 155-162.

11. Neumark D., Burn I., Button P. Is it harder for older workers to find jobs? New and improved evidence from a field experiment // Journal of Political Economy. - 2019. - V. 127. - № 2. - P. 922-970.

12. Van Ours J.C., Stoeldraijer L. Age, wage and productivity in Dutch manufacturing // De Economist. 2011. - V. 159. - № 2. - P. 113-137.

13. Кулькова И.А. Влияние занятости лиц старшего возраста на социальные и демографические процессы // Креативная экономика. - 2020. - Т. 14. - № 11. - С. 2659-2670.

14. Ляшок В.Ю., Рощин С.Ю. Молодые и пожилые работники на российском рынке труда: являются ли они конкурентами? // Журнал новой экономической ассоциации. - 2017. - № 1. - С. 117-140.

15. Van Ours J.C. Will you still need me: when I'm 64? // De Economist. - 2009. - V. 157. - № 4. - P. $441-460$.

16. Кошарная Г.Б., Щанина Е.В. Факторы депривации пожилых людей в социально-трудовой сфере: региональный аспект // Вестник Российского университета дружбы народов. Серия «Социология». 2019. - Т. 19. - № 3. - С. 481-493.

17. Смирнов С.Н. Региональные аспекты социальной экономики. - М.: Гелиос АРВ, 2004. -130 с.

18. Lutz W., Sanderson W., Scherbov S. Global and regional population ageing: how certain are we of its dimensions? // Population Ageing. - 2008. - № 1. - P. 75-97.

19. Geetha R., Swamy T., Revathi K. Impact of demographic profile on quality of work life of employees in cooperative and private sugar mills in Tamil Nadu // Technology. - 2018. - V. 9. - № 7. - P. 787-793.

20. Лебедев В.В., Лебедев К.В. Использование коэффициента Пальмы для анализа дифференциации населения по доходам // ЭТАП: экономическая теория, анализ, практика. - 2019. - № 5. - С. 70-81.

21. Комплексное наблюдение условий жизни населения. - URL: https://rosstat.gov.ru/free_doc/new_site/ KOUZ18/index.html (дата обращения 12.06.2020).

Поступила: 20.08.2021 г. 
UDC 331.101.264:316.346-053.9(47+57)

\title{
REGIONAL LABOR BEHAVIOR PROFILE OF THE OLDER PEOPLE OF THE RUSSIAN FEDERATION
}

\author{
Elena I. Klemasheva1, \\ eik15@tpu.ru \\ Lyubov I. Ivankina1, \\ ivankina@tpu.ru \\ Ekaterina A. Taran', \\ etaran@hse.ru \\ Elmira R. Kashapova ${ }^{1}$, \\ elmira@tpu.ru \\ Casati Fabio', \\ kasati@tpu.ru \\ ${ }^{1}$ National Research Tomsk Polytechnic University, \\ 30, Lenin avenue, Tomsk, 634050, Russia \\ 2 HSE University, \\ 20, Myasnitskaya street, Moscow, 101000, Russia
}

Elena I. Klemasheva, Cand. Sc., associate professor, National Research Tomsk Polytechnic University.

Lyubov I. Ivankina, Dr. Sc., professor, leading researcher, International Scientific Educational Laboratory for the Improvement of Wellbeing Technologies of Older Adults, National Research Tomsk Polytechnic University.

Ekaterina A. Taran, Cand. Sc., researcher, HSE University.

Elmira R. Kashapova, junior researcher, International Scientific Educational Laboratory for the Improvement of Wellbeing Technologies of Older Adults, National Research Tomsk Polytechnic University.

Casati Fabio, Ph.D, leading researcher, International Scientific Educational Laboratory for the Improvement of Wellbeing Technologies of Older Adults, National Research Tomsk Polytechnic University.

\begin{abstract}
The article analyzes the structure of employment of elderly people at the regional level. In the changing objective (reaching retirement age) and subjective (experiencing the transition to a new status and the adoption of new social role functions) conditions of structuring life activity, the employment of older people is also changing. Objective: to propose a typology of strategies for labor behavior at the pre-retirement stage and the stage of retirement based on the identification of motivation to engage in labor activity. Methods: analysis of sociological survey data, descriptive statistics. Sociological surveys were conducted from 2015 to 2019 in the city of Tomsk and the Tomsk region by the staff of the International Scientific and Educational Laboratory of Technologies for Improving the Well-Being of Elderly People at the Tomsk Polytechnic University and allowed forming an empirical basis for the study. The main results of sociological measurement were obtained using the statistical package SPSS-26. Results and conclusions. The analysis of the data of the sociological survey made it possible to reveal the patterns and forms of labor behavior preferred by people, a typology was carried out and a profile of the labor behavior of the older population of the Tomsk region in the context of income inequality was compiled. There are four types of labor behavior, indicators, their characteristics, subjective and objective factors. It is concluded that it is necessary to build a new model of life path in which an elderly person would not be in the position of a dependent, but would be considered as an independent, active member of society, which is the focus of the international active longevity program and the program for the implementation of action strategies in the interests of elderly citizens in the Russian
\end{abstract}


Federation until 2025. The results obtained will make it possible to form the institutional conditions for involving older people in the socio-economic system. It is concluded that for this it is necessary to ensure the economic independence of an elderly person by creating conditions for prolonging working life in accordance with the desire and ability to continue active work, as well as by accumulating capital during working life that provides a high income after leaving the field of employment, which will contribute to increasing the resilience of an elderly person and smoothing inequality.

Key words: Labor behavior, older people, labor behavior typology, resilience, involvement, labor potential.

The research was carried out due to the grant of the Russian Science Foundation (project no. 19-18-00282).

\section{REFERENCES}

1. Kulkova I. Poisk raboty kak sostavlyaushchaya trudovogo povedeniya (po rezultatam oprosa, provedennogo $\mathrm{v}$ UrFO) [Job search as a component of labor behavior (according to the results of a survey conducted in the Ural Federal District)]. Voprosy ekonomiki, 2008, no. 6, pp. 111-117.

2. Temnitsky A.L. Teoretiko-metodologicheskie podkhody k issledovaniyu trudovogo povedeniya [Theory and methodological approach to work behavior studies]. Sotsiologicheskie issledovaniya, 2007, no. 6, pp. 60-71.

3. Skolko rossiyan rabotaet na pensii. Kem oni trudyatsya i skolko zarabatyvayut [How many Russians work in retirement. What are they work and how much do they earn]. Available at: https://journal.tinkoff.ru/statpenswork/ (accessed 15 August 2021).

4. Ivanova M.A. Spros na pozhilykh rabotnikov i diskriminatsiya po vozrastu: mezhdunarodny opyt i rossiyskie realii [The demand for older workers and age discrimination: international experience and Russian realities]. Voprosy ekonomiki, 2019, no. 6, pp. 99-121.

5. Klepikova E.A., Kolosnitsyna M.G. Eydzhizm na rossiyskom rynke truda: diskriminatsiya v zarabotnoy plate [Ageism in the Russian labor market: wage discrimination]. Rossiyskiy zhurnal menedzhmenta, 2017, no. 15 (1), pp. 69-88.

6. Klepikova E.A. Vozrastnaya diskriminatsiya pri nayme: rezultaty eksperimentalnogo issledovaniya [Age discrimination in hiring: an experimental study]. Ekonomicheskaya politika, 2019, vol. 14, no. 2, pp. 64-89.

7. Pushko T.Yu. Vozrastnaya diskriminatsiya na rynke truda: spetsifika eydzhizma v Rossii [Age discrimination in the labour market: the specificity of ageism in Russia]. Sbornik nauchnykh trudov po materialam II Mezhdunarodnoy nauchno-prakticheskoy konferentsii. Sotsialno-ekonomicheskie problemy v sovremennoy nauke [Proceedings of the II International Scientific and Practical Conference. Socio-economic problems in modern science]. Moscow, Otkrytoe znanie Publ., 2017. pp. 77-78.

8. Kozina I.M., Zangieva I.K. Gosudarstvennoe i rynochnoe regulirovanie trudovoy aktivnosti pensionerov [State and market regulation of labour activity of old-age pensioners]. Zhurnal issledovaniy sotsialnoy politiki, 2018, no. 16 (1), pp. 7-22.

9. Lukianova A. Zanyatost naseleniya starshego vozrasta. Tsentr trudovykh issledovaniy NIU VSHE [Employment of the older population. HSE Center for Labor Research]. Available at: https://isp.hse.ru/data/2020/04/28/1544886314/03\%20Lukyanova_Doklad\%20KPAD_28-04-2020.pdf (accessed 12 August 2021).

10. Chistova E.V. Zaniatost lits pensionnogo vozrasta: spros i predlozhenie na rynke truda Rossii [Employment of persons of retirement age: supply and demand in the Russian labor market]. Ekonomika i biznes teoriia $i$ praktika, 2019, no. 10-2 (56), pp. 155-162.

11. Neumark D., Burn I., Button P. Is it harder for older workers to find jobs? New and improved evidence from a field experiment. Journal of Political Economy, 2019, vol. 127, no. 2, pp. 922-970.

12. Van Ours J.C., Stoeldraijer L. Age, wage and productivity in Dutch manufacturing. De Economist, 2011, vol. 159, no. 2, pp. 113-137.

13. Kulkova I.A. Vliyanie zaniatosti lits starshego vozrasta na sotsialnye i demograficheskie protsessy [Influence of the elderly employment on social and demographic processes]. Kreativnaya ekonomika, 2020, vol. 14, no. 11, pp. 2659-2670.

14. Lyashok V.Yu., Roshchin S.Yu. Molodye i pozhilye rabotniki na rossiyskom rynke truda: yavlyayutsya li oni konkurentami? [Young and older workers in the Russian labor market: are they competitors?]. Zhurnal novoy ekonomicheskoy assotsiatsii, 2017, no. 1, pp. 117-140.

15. Van Ours J.C. Will you still need me: when I'm 64? De Economist, 2009, vol. 157, no. 4, pp. 441-460. 
16. Kosharnaya G.B., Shchanina E.V. Faktory deprivatsii pozhilykh lyudey v sotsialno-trudovoy sfere: regionalny aspect [Deprivation factors for the elderly in the social labor sphere: a regional aspect]. Vestnik Rossiyskogo universiteta druzhby narodov. Seriya «Sotsiologiya», 2019, vol. 19, no. 3, pp. 481-493.

17. Smirnov S.N. Regionalnye aspekty sotsialnoy ekonomiki [Regional aspects of the social economy]. Moscow, Gelios APB Publ., 2004. 130 p.

18. Lutz W., Sanderson W., Scherbov S. Global and regional population ageing: how certain are we of its dimensions? Population Ageing, 2008, no. 1, pp. 75-97.

19. Geetha R., Swamy T., Revathi K. Impact of demographic profile on quality of work life of employees in cooperative and private sugar mills in Tamil Nadu. Technology, 2018, vol. 9, no. 7, pp. 787-793.

20. Lebedev V.V., Lebedev K.V. Ispolzovanie koeffitsienta Palmy dlya analiza differentsiatsii naseleniya po dokhodam [Using the Palm coefficient for analysis of population income differentiation]. ETAP: ekonomicheskaya teoriya, analiz, praktika, 2019, no. 5, pp. 70-81.

21. Kompleksnoe nablyudenie usloviy zhizni naseleniya [Comprehensive monitoring of the living conditions of the population]. Available at: https://rosstat.gov.ru/free_doc/new_site/KOUZ18/index.html (accessed 12 June 2020).

Received 20 August 2021. 